\title{
KARYA ALLAH PADA MASA INTERTESTAMEN
}

\author{
Yanto Paulus Hermanto \\ Sekolah Tinggi Teologi Kharisma Bandung \\ Jl. Mekar Laksana No.8, Bandung, Jawa Barat \\ Email: y_paulus@yahoo.co.id
}

\begin{abstract}
Yanto Paulus Hermanto. From the prophetic word of Malachi (432 BC) to the event of God's Angel spoke to priest Zechariah, John the Baptist's father, is estimated to be about 400 years. Over that long period, what really happened? Was God silent? Or was God preparing the coming of the Messiah? Or wasGod angry with His people, who continued to sin? These questions are the debated matters among the theologians. The author tries to collect data from previous studies of historical events, archeological findings, and Biblical text. Thus it can be deduced a conclusion, what is actually happening in the period of 400 years. Research begins from the years before, during the intertestament and the time afterward. The study will cover the history of Persian media, Greek (Hellenistic), Jews regain Jerusalem (Maccabeanrevolt) and the establishment of the Roman empire. Based on the research, it is found a reality, that during the intertestamental era, God had an active role. The fulfillment of Daniel, Hosea and Malachi's prophecies occurred during the intertestament. Even supernatural things, which would not have been possible without God intervention, had occurred. This research will certainly convince all readers, that God is still working and in control in every age.
\end{abstract}

Key Words: Intertestament, Persian, Hellenistic, Maccabee, Roman, God's work

\begin{abstract}
Abstrak: Yanto Paulus Hermanto. Dari perkataan nubuat nabi Maleakhi (432 SM) hingga malaikat Tuhan berbicara kepada Imam Zakaria, bapaknya Yohanes pembaptis diperkirakan 400 tahun.Dan sepanjang periode waktu yang panjang tersebut, apakah yang terjadi? Apakah Allah berdiam diri? Atau apakah Ia sedang mempersiapkan kedatangan Mesias? Atau Allah marah terhadap umat-Nya yang terus hidup dalam dosa? Pertanyaan-pertanyaan ini yang seringkali menjadi perdebatan para teolog. Penulis mencoba mengumpulkan dari peristiwa-peristiwa sejarah yang telah diteliti sebelumnya, hasil-hasil arkelogi, dan teks Alkitab yang berkaitan. Penelitian dimulai dari tahun-tahun sebelum, selama dan setelah masa intertestamen.Hal-hal yang dipelajari meliputi sejarah Media Persia, Yunani (Helenisasi), kembalinya orang Yahudi ke Yerusalem (pemberontakan Makabe) dan terbentuknya kerajaan Romawi. Setelah melakukan penelitian, maka diperoleh realitas bahwa Allah berperan secara aktif dalam masa tersebut. Penggenapan Nubuat dalam Daniel, Hosea dan Maleaki terjadi pada masa intertestamen. Bahkan hal-hal yang supernatural, tidak mungkin terjadi, jika bukan Allah yang mengintervensi hal-hal tersebut. Hasil penelitianini tentu menyakinkan para pembaca bahwa Allah masih dan sedang bekerja dan mengontrol dalam segala zaman.
\end{abstract}

Kata kunci: Intertestamen, Persia, Helenisasi, Makabe, Romawi, Karya Allah

\section{PENDAHULUAN}

Tahun 722 SM bangsa Israel dikalahkan oleh Asiria dan diangkutlah ribuan orang Israel untuk ditempatkan di wilayah bagian Asiria (Taylor, 2005, p. 5). Sedangkan bangsa Yehuda mengalami pembuangan sebanyak tiga kali. Tahun 597SM, 587 SM, dan tahun 582SM ke wilayah Babel (Stalling dan Kichen, 2001, p. 464, 560). Ketika mereka berada di masa pembuangan tersebut Allah tetap berbicara melalui nabi-nabi-Nya. Begitu pun setelah masa pembuangan, Allah tetap berbicara. Namun tidak da- pat dipungkiri ada satu masa, sepertinya Allah berdiam dan tidak berbicara kepada umat-Nya, yakni masa yang sering disebut masa antara Perjanjian Lama dan Perjanjian Baru atau masa intertestament.

Ada dua kitab yang penulisannya paling muda dan menjadi tulisan terakhir dalam Perjanjian Lama, yakni Kitab Maleakhi dan Kitab Tawarikh. Kitab Maleakhi diperkirakan ditulis pada tahun 450 SM atau sebelum itu (Weyde, 2000, p. 5), sedangkan Kitab Tawarikh diperkirakan ditulis tahun 475-425 SM (Kalimi, 2005, p.8). Sedangkan kitab di Perjan- 
jian Baru yang paling tua penulisannya adalah Injil Markus, yang diperkirakan ditulis pada tahun 55-65 M (Stalling\& Kichen, 2001, p. 30). Jadi ada sekitar 485 tahun tenggang waktu dari penulisan kitab Perjanjian Lama terakhir dan penulisan kitab Perjanjian Baru yang pertama.

Pada tahun 444 SM atas seizin raja Artahsasta, raja Persia, Nehemia tiba di Yerusalem dan memimpin orang-orang untuk membangun kembali tembok kota Yerusalem (Neh.2-6). Setelah pembangunan tembok Yerusalem selesai. Untuk sementara waktu Nehemia kembali ke raja Artasasta untuk melapor. Namun ketika Nehemia kembali ke Yehuda, ke kota Yerusalem, maka didapati orang-orang Yehuda berbuat jahat kepada Tuhan. Mereka kawin dengan bangsa lain, tidak mengindahkan hari sabat, tidak menghormati rumah Allah, sumbangan untuk para Lewi tidak pernah diberikan, tidak memberikan persembahan persepuluhan dan mereka berubah setia terhadap Allah (Neh. 13). Mereka memiliki moralitas dan ketaatan yang semakin rusak (Bennema, 2001. p. 64).

Saat kondisi orang-orang Yerusalem seperti demikian, Tuhan mengirim nabi Maleakhi (432 SM) untuk menyampaikan firman-Nya (Taylor, 2005, p. 4). Melalui nabi Maleakhi Tuhan marah karena Israel tidak hormat dan takut akan Allah. Mereka membawa persembahan yang cacat dan cemar ke atas mezbah, para imamnya menyimpang dari jalan yang ditunjukkan Tuhan, menajiskan tempat kudus Tuhan, mereka kawin dengan perempuan keturunan bangsa lain dan melakukan perceraian dengan istri yang sahnya.

Namun melalui nabi Maleakhi juga Allah berfirman, bahwa Ia akan menyuruh utusan-Nya untuk mempersiapkan jalan dihadapan-Nya (Mal. 3:1). Nubuat ini menjadi kenyataan 400 tahun kemudian, dengan lahirnya Yohanes pembaptis yang mendahului kelahiran Yesus Kristus (Mat. 11:10; Mrk. 1:2; Luk. 1:76, 7:27) (Taylor, 2005, p. 4). Melalui dia akan dibuat hati bapa-bapa berbalik kepada anakanaknya dan hati anak-anak kepada bapa-bapanya (Mal. 4:6).
Dari firman yang disampaikan oleh nabi Maleakhi (432 SM) hingga malaikat Tuhan berbicara kepada imam Zakharia, bapaknya Yohanes pembaptis, diperkirakan sekitar 400 tahun (Ekstrand, 2004, p. 1). Selama jangka waktu yang panjang tersebut, apa yang sebenarnya terjadi? Apakah memang Tuhan sedang berdiam? Atau Tuhan sedang mempersiapkan kedatangan Sang Mesias? Atau Tuhan sedang murka kepada umat-Nya, yang terus melakukan dosa? Pertanyaan-pertanyaan ini tentu menjadi daya tarik para teolog untuk melakukan penelitian. Selain itu, tentu penulis meyakini ada pembelajaran yang berharga dari setiap peristiwa sejarah yang terjadi, yang bisa diambil manfaatnya untuk kehidupan masa kini.

Sesuai uraian di atas, maka penelitian ini dilakukan untuk mengetahui apa yang terjadi pada masa intertestamen tersebut. Baik yang melatarbelakangi munculnya peristiwa di masa intertestamen maupun nubuat-nubut dari Perjanjian Lama yang digenapi pada masa tersebut. Selain itu penelitian ini pun dilakukan untuk mengetahui apakah ada campur tangan Allah dalam sejarah masa tersebut. Seperti yang diyakini oleh para providensialis bahwa setiap sejarah yang terjadi di dunia ini tidak lepas dari campur tangan Allah (Guyatt, 2007. p. 1607).

Oleh sebab itu tujuan penelitan ini adalah untuk menjawab rumusan masalah di atas, yakni untuk meneliti apa saja yang terjadi pada masa intertestamen dan untuk meneliti apa yang melatar belakangi kejadian-kejadian tersebut, baik dari sejarah, penemuan arkeologi maupun dari penggenapan nubuat-nubuat yang ada di Perjanjian Lama. Dan juga untuk mengetahui apa saja campur tangan Allah pada masa intertestamen tersebut.

\section{METODE}

Penulis mencoba menggunakan pendekatan kualitatif dalam penelitian ini dan mengumpulkan data dari berbagai buku sejarah dari masa pembuangan bangsa Israel dan Yehuda sampai masa kerajaan Romawi, jurnal yang terkait serta data arkeologi. Tahun-tahun terjadinya peristiwa tersebut dite- 
lusuri dari berbagai sumber sehingga ditemukan tahun-tahun yang mendekati kebenarannya, dengan cara membandingkan banyaknya buku dan jurnal yang memiliki persamaan tahun kejadiannya. Begitu pula hasil-hasil arkeologi yang menunjukkan kebenaran dari peristiwa-peristiwa pada masa tersebut, dan yang paling utama adalah Alkitab menuliskan kejadian tersebut dengan rinci.

Semua data tersebut dipelajari dengan seksama, dibandingkan satu dengan yang lainnya dan akhirnya diperoleh kaitan satu peristiwa dengan peristiwa lainnya. Penulis menjadikan Alkitab sebagai patokan dan dasar yang benar. Jadi semua peristiwa mendukung apa yang dikatakan Alkitab sebagai nubuatannya. Dalam hal ini penulis menggunakan nubuatan dari kitab Daniel, Nehemia, Maleakhi dan penggenapanya terjadi pada masa intertestamen dan masa kerajaan Romawi di Perjanjian Baru. Masa Yohanes pembaptis sampai murid-murid Yesus, merupakan bukti yang dapat ditelusuri kepada peristiwa-peristiwa yang terjadi sebelumnya.

Akhirnya dari semua buku, jurnal, hasil arkelogi, dan nubuat dalam Alkitab menjadi suatu karya tulis ilmiah yang dapat menjawab apa yang sebenarnya sedang terjadi pada masa intertestamen itu. Juga penulis berharap karya tulis ini akhirnya dapat menjadi acuan bagi semua pembaca baik para akademisi, pendeta maupun jemaat yang ingin menelusuri karya Allah pada masa intertestamen.

\section{HASIL DAN PEMBAHASAN}

\section{Nubuat Melalui Daniel Tergenapi}

Media Persia adalah negara yang selama 600 tahun telah menaklukkan wilayah-wilayah Yunani di Asia. Pada tahun 499-494 SM, Darius, kaisar Persia memutuskan untuk menaklukkan seluruh wilayah Yunani, termasuk yang di dataran Eropa (Taylor, 2005, p. 4). Media Persia terus melakukan ekspansi dengan segala kekuatannya. Mereka pun mencoba menguasai wilayah Athena yang terletak di Yunani timur, beberapa mil letaknya dari laut Aegea. Beberapa kali pertempuran terjadi antara Persia dan
Athena. Athena masih bisa mempertahankan daerahnya meskipun korban jiwa yang cukup banyak telah dikorbankan.

Athena tetap berdiri kokoh dengan konfederasi lebih dari 200 wilayah di sekitar laut Aegea. Konfederasi tersebut sebenarnya merupakan konfederasi kesetaraan, karena semua anggotanya merupakan wilayah yang mempunyai hak yang sama, termasuk Athena. Namun karena sikap Athena berusaha menguasai konfederasi tersebut. Maka wilayahwilayah lain mulai waspada kalau-kalau mereka pun akan dikuasai oleh Athena.

Perbedaaan pendapat dan kecurigaan di antara wilayah-wilayah tersebut mencapai puncaknya pada tahun 431-404 SM (Taylor, 2005, p. 83). Lacedaemonia, yang merupakan orang-orang Sparta menyerang Athena.Orang-orang Athena terdesak oleh kekuatan angkatan darat Lacedaemonia, sehingga mereka berkumpul di suatu tempat dan mengimpor makanan melalui jalan laut. Namun demikian lambat laun Athena mengalami berbagai penderitaan. Mereka mengalami wabah penyakit dan dengan cepat menyebar, karena wilayah yang kecil di mana mereka bermukim dengan jumlah penduduk yang banyak. Wabah ini menyebabkan kematian hampir seperempat penduduk Athena, bahkan raja Pericles pun meninggal tahun 429 SM.

Pada tahun 404 SM, Athena dikalahkan oleh Lacedaemonia dengan bantuan Persia. Namun sebenarnya peperangan antar konfederasi di sekitar laut Aegea merupakan kekalahan mereka semua. Kekuatan konfederasi ini semakin melemah, mereka tidak dapat bersatu. Dalam kondisi yang seperti ini, muncul negara Makedonia, yang berasal dari ujung laut Aegea. Negara ini tidak diperhitungkan, karena kecil dan tidak berpengaruh. Namun ketika Makedonia mulai menyerang mereka, mereka kewalahan dan akhirnya harus tunduk pada kekuasaan mereka.

Tahun 359-336 SM, Raja Philip memerintah Makedonia (Taylor, 2005 p. 85). Di bawah pemerintahannya Makedonia menjadi negara yang tangguh. Semua wilayah konfederasi di sekitar laut Aegea tunduk kepadanya. Namun pada tahun 336 
SM, Philip dipaksa turun takhta, dia dibunuh atas hasutan mantan istrinya. Maka Alexander, anaknya yang naik takhta, menggantikan dia. Alexander yang baru berusia 20 tahun mendapat bimbingan dari Aristoteles. Dia seorang raja yang mempunyai ambisi yang besar untuk menaklukkan dunia. Cita-citanya mulai menjadi kenyataan dengan menguasai Asia kecil, menaklukkan Persia, kemudian menaklukkan Mesir dan juga daerah-daerah sebelah timur Persia, wilayah Kanaan bahkan sampai ke India.

Penguasaan yang fantastik dari Alexander Agung ini berjalan bertahun-tahun.Namun tanpa diduga pada tahun $323 \mathrm{SM}$, saat Alexander berusia 30 tahun, dia meninggal secara mendadak (Taylor, 2005, p. 86). Setelah Alexander meninggal, maka jenderal-jenderalnya yang selama Alexander hidup bersaing mengambil kendali kerajaan.Dengan pergolakan di antara para petinggi kerajaan tersebut, kondisi kerajaan menjadi lemah dan semakin terpuruk.

Kondisi seperti ini dimanfaatkan oleh para Jenderal Makedonia untuk memperoleh kekuasaan. Sehingga pada awal abad ke-3 terpecahlah negara ini menjadi empat bagian. Pertama, negara Makedonia itu sendiri meliputi daerah-daerah disekitar laut Aegea di bawah pimpinan Cassander. Kedua, Mesir yang diperintah oleh Ptolemy, dengan ibukotanya di Alexandria. Ketiga, Syria di bawah dinasti Seleucid dengan pusat pemerintahannya di Antiokhia. Keempat, Kerajaan Troas dan Bythynia, yang merupakan pusat perdagangan di Mediterania timur dipimpin oleh Lysimachus (Taylor, 2005, p. 18). Keempat negara ini tidak mempunyai kekuatan seperti Makedonia yang awal ketika di bawah kekuasaan Alexander Agung. Empat negara yang baru berdiri ini jauh lebih lemah. Hal ini diakibatkan karenabeberapa hal seperti berikut: pertama, melakukan perang yang terus menerus, kedua, orang-orang di dalam pemerintahannya saling memperebutkan kekuasaan. Contoh yang nyata adalah antara Ptolemy dan Seleucid yang terus memperebutkan pantai Mediterania (Beckwith, 2002 , p. 77). Ketiga, adanya gap yang besar antara penduduk yang kaya dan yang miskin. Dengan demikian keempat negara ini lebih banyak waktu dan tenaga digunakan untuk mengurusi permasalahan dan kekuasaan yang ada di dalam negerinya saja.

Keadaan tersebut, membuat mereka dengan mudah dikalahkan dan dikuasai oleh negara lain. Pada tahun 146 SM Republik Roma menaklukannya. Padahal awalnya Roma hanyalah negara yang kecil, jauh lebih kecil jika dibandingkan dengan Athena dan Lacedaemonia pada masa kejayaan mereka. Republik Roma dengan kekuatan tentaranya yang terlatih menguasai jauh lebih banyak dari pada yang telah dilakukan oleh Makedonia.

Dari kenyataan sejarah negara-negara yang muncul dan tenggelam ini. Penulis mencoba mendalami apakah ada campur tangan atau pekerjaan Allah dalam peristiwa-pertistiwa tersebut. Dalam kitab Daniel pasal 8:3-9 dicatat sebagai berikut:

Aku mengangkat mukaku dan melihat, tampak seekor domba jantan berdiri di depan sungai itu; tanduknya dua dan kedua tanduk itu tinggi, tetapi yang satu lebih tinggi dari yang lain, dan yang tinggi itu tumbuh terakhir. Aku melihat domba jantan itu menanduk ke barat, ke utara dan ke selatan, dan tidak ada seekor binatang pun yang tahan menghadapi dia, dan tidak ada yang dapat membebaskan dari kuasanya; ia berbuat sekehendak hatinya dan membesarkan diri. Tetapi sementara aku memperhatikannya, tampak seekor kambing jantan datang dari sebelah barat, yang melintasi seluruh bumi tanpa menginjak tanah; dan kambing jantan itu mempunyai satu tanduk yang aneh di antara kedua matanya. Ia datang pada domba jantan yang dua tanduknya dan yang kulihat berdiri di depan sungai itu, lalu menyerangnya dengan keganasan yang hebat. Aku melihatnya mendekati domba jantan itu; ia menggeram, lalu ditanduknya domba jantan itu, dipatahkannya kedua tanduknya, dan domba jantan itu tidak berdaya untuk tahan menghadapi dia; dihempaskannya dia ke bumi, diinjak-injaknya, dan tidak ada yang melepaskan domba jantan itu dari kuasanya. Kambing jantan itu sangat membesarkan dirinya, tetapi ketika ia sampai pada puncak kuasanya, patahlah tanduk yang besar itu, lalu pada tempatnya tumbuh empat tanduk yang aneh, sejajar dengan keempat mata angin yang dari langit. Maka dari salah satu tanduk itu muncul suatu tanduk kecil, yang menjadi sangat besar ke arah selatan, ke arah timur dan ke arah Tanah Permai (LAI, Alkitab TB). 
Kemudian mulai ayat ke 20, Tuhan menjelaskan kepada Daniel melalui malaikat Gabriel sebagai berikut:

Domba jantan yang kaulihat itu, dengan kedua tanduknya, ialah raja-raja orang Media dan Persia. Dan kambing jantan yang berbulu kesatitu ialah raja negeri Yunani, dan tanduk besar di antara kedua matanya itu ialah raja yang pertama. Dan bahwa tanduk itu patah dan pada tempatnya itu muncul empat buah, berarti: empat kerajaan akan muncul dari bangsa itu, tetapi tidak sekuat yang terdahulu. Dan pada akhir kerajaan mereka, apabila orang-orang fasik telah penuh kejahatannya, maka akan muncul seorang raja dengan muka yang garang dan yang pandai menipu. Kekuatannya akan menjadi hebat, tetapi tidak sekuat yang terdahulu, dan ia akan mendatangkan kebinasaan yang mengerikan, dan apa yang dilakukannya akan berhasil; orang-orang berkuasa akan dibinasakannya, juga umat orang kudus. Dan oleh karena akalnya, penipuan yang dilakukannya akan berhasil; ia akan membesarkan dirinya dalam hatinya, dan dengan tak disangka-sangka banyak orang akan dibinasakannya; juga ia akan bangkit melawan Raja segala raja. Tetapi tanpa perbuatan tangan manusia, ia akan dihancurkan (LAI, Alkitab Terjemahan Baru).

Penulisan kitab Daniel ini diperkirakan sekitar tahun 536-530 SM. Jadi apa yang terjadi dalam sejarah yang diuraikan di atas merupakan kejadiankejadian setelah penulisan kitab tersebut sekitar seratus tahun lebih kemudian. Kitab Daniel adalah kitab sejarah, namun di dalamnya terdapat nubuat-nubuat terhadap hal-hal yang akan terjadi di kemudian hari.

Dari uraian yang ditulis melalui Daniel tersebut dinyatakan bahwa domba jantan tersebut adalah raja-raja orang Media dan Persia, sedangkan kambing jantan yang berbulu kesat itu adalah raja negeri Yunani. Tanduk yang besar pada kambing jantan adalah raja pertama, sedangkan empat tanduk yang muncul setelah tanduk yang pertama patah adalah empat kerajaan yang muncul dari bangsa Yunani yang pertama tersebut. Keempat kerajaan tersebut tidak sekuat yang pertama. Kemudian munculah seorang raja yang lain yang tak disangka-sangka mem- binasakan banyak orang, termasuk umat orang kudus dan melawan Raja segala raja.

Setelah melihat kronologis sejarah yang telah diuraikan di atas secara ringkas namun menyeluruh maka jelas sekali semua nubuatan itu tergenapi pada periode masa intertestament. Dimulainya dari jaman kejayaan Persia dari tahun 499-330 SM, kemudian Persia dikalahkan oleh kerajaan Yunani (330-146 SM), ketika Alexander Agung berkuasa. Setelah Alexander wafat tahun 323 SM, munculah empat negara yang berasal dari negara Yunani tersebut yakni Makedonia, Mesir, Syria, Troas dan Bytinia. Keempat negara yang kemudian ini lebih lemah dari yang pertama.

Kemudian tanpa diduga, satu tempat di sebelah barat laut Aegea muncul menjadi negara yang besar dan sanggup menaklukkan Yunani dan bangsa-bangsa lainnya. Negara ini adalah republik Roma, yang merupakan cikal bakal dari kerajaan Romawi. Kerajaan Romawi berdiri hingga zaman Yesus Kristus. Melalui kerajaan Romawi inilah banyak umat Tuhan yang dibinasakan secara kejam, bahkan Yesus Kristus yang adalah Raja segala raja mengalami penganiayaan sampai akhirnya disalibkan dan mati di atas kayu salib.

Semua nubuat Daniel tersebut terjadi pada periode masa intertestamen hingga setelah era Yesus. Hal ini menandakan bahwa Allah tetap bekerja dan campur tangan di segala zaman. Tidak ada satu masa pun Allah tidak bekerja (Henry, 2007).

\section{Helenisasi pada Masa Intertestamen}

Helenisasi dimulai sejak kekuasaan Makedonia oleh Alexander Agung. Setelah menaklukan kekaisaran Persia tahun 334 SM, ia terus bergerak ke timur bersama tentaranya menaklukan Afganistan, Uzbekistan dan Tajikistan. Kemudian ke selatan menaklukan Rusia dan terus melintasi lembah sungai Indus ke India.

Alexander pun menjelajahi selatan dari Asia kecil, Syria, Mesir dan akhirnya membawa Palestina di bawah pemerintahannya. Di Mesir, Alexander mendirikan sebuah kota baru di pesisir pantai dan di- 
namai kota itu Alexandria. Alexander tidak pernah kembali ke Yunani, dan malah mendirikan pengadilan di Babel. Penaklukan yang dilakukan oleh Alexander berdampak cukup besar dan lama. Penaklukan yang dilakukan oleh Alexander ini sebagai Helenistik ("Seperti Yunani”). Hampir semua daerah yang dia taklukkan diperkenalkan secara langsung kepada kebudayaan dan bahasa Yunani. Alexander mempromosikan budaya Yunani dengan mendirikan istana yang bergaya oriental di Babel dan mendorong tentara Makedonia untuk menikahi wanita pribumi.

Penerus Alexander mempromosikan penyebaran bahasa Yunani, adat istiadat, agama, gaya arsitektur dan seni ke timur dekat. Di sisi lain budaya timur dekat mempengaruhi juga orang-orang Yunani, misalnya mereka menyembah Alexander dan penerusnya sebagai makhluk yang didewakan, layaknya seperti Firaun di Mesir. Setelah Alexander wafat, maka kekaisarannya terbagi empat yang diperebutkan oleh para jenderalnya. Dua jenderal Alexander yang merebut bagian terbesar kekaisaran yakni Seleucid menguasai daerah Asia Kecil, Syria dan Mesopotamia, sedangkan Ptolemy menguasai kerajaan Mesir. Helenisasi terus berjalan sampai terjadi pemberontakan Macca-bee tahun 167 SM.
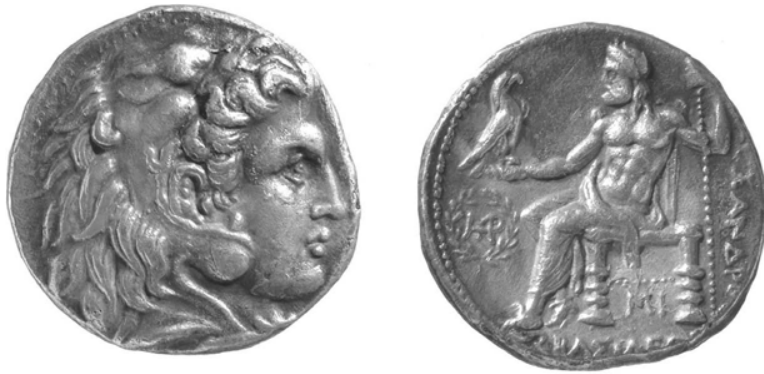

Coin of Alexander the Great. Courtesy of Zev

Radovan/BibleLandPictures.com (Magness, 2012, p. 85)

\section{Perjanjian Lama Diterjemahkan ke dalam bahasa Yunani}

Tahun 270 SM, Raja Ptolemy II Philadelphus dari Mesir, memutuskan untuk memiliki Taurat (Pentateukh) yang diterjemahkan ke dalam bahasa Yunani dan menambahkannya ke perpustakaan barunya di Alexandria (Louis H. Feldman, 1996, p.18).
Keinginan Ptolemy II sangatlah beralasan. Hellenisme menjadikan orang-orang Yahudi yang banyak tinggal di Alexandria sudah semakin melupakan bahasanya karena telah beralih ke bahasa Yunani.Hal inilah yang menyebabkan adanya upaya untuk menerjemahkan Alkitab Perjanjian Lama ke dalam Bahasa Yunani tentu dengan maksud agar masyarakat Yahudi dapat memahaminya.

Catatan pembuatan atau penerjemahan Taurat dari bahasa aslinya ke dalam bahasa Yunani menyatakan bahwa penerjemahannya dilakukan oleh 72 tua-tua (Taylor, 2005. p. 20) yang didatangkan dari Yerusalem, yang sering disebut "septuaginta". Dan para komunitas orang Yahudi di Alexandria menganggap terjemahan tersebut begitu sempurna sehingga tidak boleh dilakukan perubahan sedikit pun. Begitu pun ketika terjemahan tersebut dibacakan di hadapan para imam, penatua dan penerjemah dari badan korporat, mereka menyatakan kekagumannya akan karya terjemahan tersebut dan mengatakan: "terjemahan ini telah dilakukan dengan baik, benar dan akurat secara detailnya. Kami menaruh rasa hormat dan sepantasnya tetap seperti ini, tidak boleh ada revisi. Dan sesuai adat istiadat, jika ada yang menyetujui dan atau memerintahkan revisi, maka baginya diperintahkan untuk mengucapkan kutuk kepada siapa saja yang merevisinya dengan menambahkan ataupun mengurangi yang telah tertulis."

Penerjemahan dilakukan di pulau Pharos, dekat pantai Alexandria. Tujuh puluh dua penerjemah berada di ruang yang berbeda-beda, namun mereka menterjemahkan Taurat Tuhan tersebut benarbenar sama dan sempurna. Dan tentu dengan hasil yang demikian semua imam dan penatua meyakini ada campur tangan Ilahi dalam hal tersebut.Seperti yang disampaikan oleh Louis:

Rabbi Judah [bar Ilai, mid-second century CE] said: When our teacherspermitted Greek, they permitted it only for a scroll of the Torah. Thiswas on account of the incident related in connection with King Ptolemy[Philadelphus], as it has been taught: 'It is related of King Ptolemy thathe brought together seventy-two elders and placed them in seventytwo [separate] rooms, without telling them why he had brought 
themtogether, and he went in to each one of them and said to him, "Translate for me the Torah of Moses your master" God then prompted each one of them and they all conceived the same idea (Taylor, 2005, p. 22)

Untuk mengenang hal ini, maka setiap tahun diadakan pertemuan yang dihadiri oleh orang Yahudi dan non Yahudi di pulau Pharos untuk memperingati terjemahan septuaginta yang menakjubkan tersebut. Mereka meyakini bahwa raja Ptolomeus diberikan hati yang penuh kasih oleh Allah untuk menerjemahkan Taurat, agar bisa dibaca oleh khususnya orangorang Yahudi dan umumnya oleh semua orang di dunia ini.

Mereka memperingati bahwa para penerjemah yang menulis ada di bawah ilham dari Allah, seolah-olah mereka didikte oleh pembisik yang tidak terlihat. Karena bahasa Yunani itu unik, pola atau bentuk kalimatnya yang bisa berubah dan frase yang utuh dan tidak utuh bisa berbeda sesuai ekpresi suatu aktifitas tertentu. Dan mereka berkumpul untuk bersyukur dan untuk menghormati tempat itu; di mana telah terjadi hal yang menakjubkan bagi mereka.

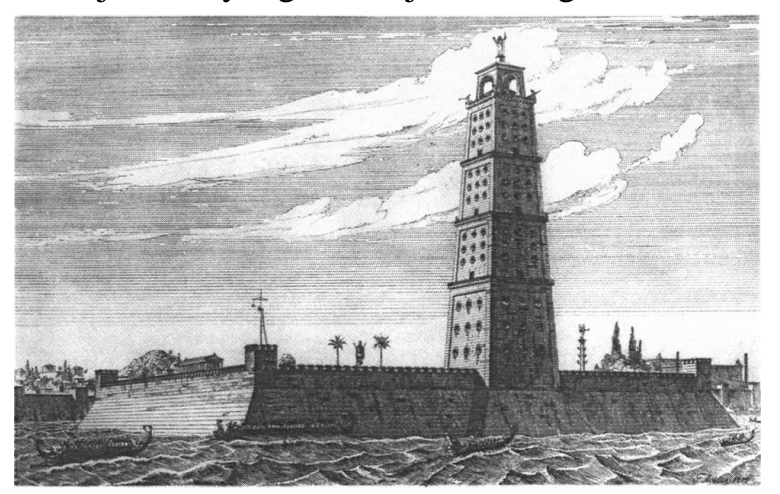

The Pharos Lighthouse of Alexandria

(reconstruction after Adler), built by Sostratus of

Cnidus for Ptolemy 11, ca (Taylor, 2005, p. 15)

\section{Orang-orang Yahudi Berbahasa Yunani}

Orang-orang Yahudi berbahasa Yunani dimulai abad ke-3. Orang-orang Yahudi umumya menggunakan bahasa Yunani, layaknya orang-orang Yunani. Hal ini ditunjukkan dari papyrus pada periode tersebut. Mereka berkumpul dalam satu kota Yunani sebagai pendatang, dan mereka diorganisir oleh suatu perhimpunan yang dinamakan "politeu- ma”. Mereka diberi hak untuk hidup sesuai dengan kebiasaan bapak leluhur mereka.Disetiap tempat mereka bermukim ada sinagog, sebagai pusat keagamaan dan sosial komunal mereka. Orang-orang Yahudi tersebar ke berbagai tempat dan terus menggunakan bahasa Yunani, bahkan ada yang menggunakan nama pribadi Yunani. Orang-orang Yahudi terus menyebar dalam jumlah yang besar ke banyak daerah Helenistik terutama Kirene (Libia), Yunani, laut Aegea, Syria, Roma, seluruh Italia, Alexandria, Antiokhia (Suriah) dan ke Sri Lanka (kerajaan Seleucid) (Sugihardjo, 1989, p. 85-90). Di Kirene, orang-orang Yahudi mendapat kesetaraan kewarganegaraan dengan penduduk setempat. Mereka dibantu oleh Ptolomeus untuk memperluas kelompok Yahudi di daerah tersebut menjadi komunitas Yahudi yang kelak dipersiapkan untuk melakukan pemberontakan terhadap Republik Roma. Di Yunani, orang-orang Yahudi mendapat kebebasan dari raja. Di Syria, mereka pun mendapat kesetaraan hak sama dengan orang Yunani dan dapat hidup dengan aman. Komunitas Yahudi di kekaisaran Roma ini adalah yang terbesar. Jumlah mereka mencapai 50.000 orang, dan hampir semuanya berbahasa Yunani. Hal ini terbukti dari beberapa prasasti yang ditemukan. Begitu pun di daerah lain, meskipun jumlahnya lebih sedikit.

Bahasa Yunani yang sudah digunakan hampir oleh seluruh orang Yahudi tentu memberikan dampak yang besar terhadap budaya dari orang Yahudi itu sendiri. Tata cara keagamaan, hasil-hasil seni yang nampak sebagai seni Yahudi Helenistik, juga bagi tahun-tahun setelah Kristus hadir di bumi memberikan pengaruh yang sedemikan cepat bagi pertumbuhan kekristenan. Menurut Levine helenisasi yang terjadi pada waktu kekuasaan Yunani hingga Romawi memiliki pengaruh terhadap keseluruhan wilayah penyebaran Injil. Hal ini tentu memudahkan karena bahasa yang digunakan sama (Levine, 1998, p. 5). Berdasarkan uraian di atas dan penegasan dari Levin, penulis meyakini bahwa Allah tetap bekerja dengan luar biasa. Dia sedang menyiapkan jalan untuk mewartakan Injil keselamatan bagi semua bangsa melalui helenisasi ini. 


\section{Pemberontakan Maccabee pada Masa \\ Intertestement}

Pemberontakan orang Yahudi ini menjadi preseden dalam sejarah manusia. Perang idelogis atau agama terjadi tahun 138 SM (Spiro, 2008, p.2). Orang-orang Yahudi menganggap agama mereka adalah agama satu-satunya yang monoteistik pada saat itu. Oleh sebab itu, ketika pasukan Yunani dari kota Modi' in mengintruksikan untuk membawa babi hutan dan menyerahkannya bagi dewa Yunani mereka menolaknya. Penatua kota, Mattathias, yang adalah seorangimam, berkata,

Even if all the nations that live under the rule of the king obey him, and have chosen to do his commandments, departing each one fromthe religion of his fathers, yet I and my sons and my brothers will liveby the covenant of our fathers ... We will not obey the king's word byturning aside from our religion to the right or to the left (Spiro, 2008, p.2).

Mattathias menyatakan hal ini kepada tentara-tentara Yunani sebagai tanda kesetiaannya kepada Tuhan.

Ini merupakan pernyataan dan tekad dari Mattathias dan seluruh keluarganya terhadap kondisi bait Allah yang dinajiskan. Dikisahkan bahwa ada seorang Yahudi Hellenis di kota tersebut melakukan apa yang diperintahkan oleh pasukan Yunani tersebut untuk mengorbankan babi, maka Mattathias segera menusuk dan membunuhnya, dan di saat yang sama diapun membunuh pejabat Yunani yang sedang hadir di sana. Kemudian Mattathias berdiri dan mengumumkan kepada semua orang Yahudi yang hadir untuk mengikuti tekadnya untuk berada di bawah hukum Tuhan. Mereka yang bergabung dengan Mattathias dan kelima anaknya (bernama Judah, Johanan, Simon, Elazar, Yonatan) menuju bukit-bukit, mengharapkan orang-orang Yunani akan kembali dan menghapus seluruh desa sebagai pembalasan. Dalam bukit, mereka mengorganisir sebuah tentara gerilya, yang dipimpin terutama oleh anak tertua bernama Judah, dijuluki Maccabee, yang berarti "the Hammer" Maccabee (Spiro, 2008, p.2). Pengikut Maccabee diperkirakan tidak lebih dari 12.000 orang, sedangkan pasukan Yunani lebih dari 40.000 orang
(Spiro, 2008, p.3). Pasukan Yunani merupakan tentara profesional, mereka memiliki peralatan, terlatih, dan memiliki kawanan gajah perang, yang merupakan tank perang jaman kuno. Orang Yahudi sangat kalah jumlah, kurang terlatih dan kurang peralatan perang, tapi yang mereka punya adalah semangat untuk tunduk pada Allah mereka. Sebagian besar pertempuran terjadi di kaki bukit yang mengarah ke daerah Tel Aviv. Pasukan Yunani berusaha untuk menerobos naik ngarai alam yang menuju ke daerah pegunungan yang merupakan benteng orang-orang Yahudi Maccabee. Hanya ada beberapa tempat di mana orang-orang Yunani bisa benar-benar naik, dan inilah letak kemenangan orang-orang Yahudi Maccabee. Dalam waktu beberapa minggu saja, orangorang Yahudi Maccabee menang dan pasukan Yunani pulang ke rumah. Banyak korban dari kedua belah pihak, sampai akhirnya mencapai kesepakatan damai di antara keduanya.

Setelah tiga tahun, orang-orang Yahudi berhasil menaklukkan kembali Yerusalem dan mendapati Bait Suci menjadi begitu najis dan berubah menjadi tempat suci kafir, tempat babi-babi yang dikorbankan di altar. Saat mereka memasuki Bait Suci; yang pertama kali mereka lakukan adalah mencoba menyalakan sebuah menorah seperti emas asli. Satu botol minyak telah dicairkan oleh orang Yunani tetapi ada satu botol minyak lampu murni lagi yang masih tersegel ditemukan. Mereka menggunakan minyak dari botol ini untuk menyalakanmenorah dan secara ajaib, menorah bisa tetap menyala selama delapan hari, yang sebenarnya minyak tersebut hanya cukup untuk satu hari saja. Keajaiban ini dijelaskan dalam Talmud sebagai berikut:

And when the royal Hasmonean House gained the upper hand and vanquished [the Greeks], they searched and found only one flask of oil... with the High Priest's seal, and it contained only [enough] oil to burn for one day. A miracle occurred and it burned for eight days (Talmud, p. 21b).

Orang Maccabee kemudian memurnikan Bait Allah dan mengabdikan diri mereka kembali bagi Allah pada tanggal 25 Kislev (penanggalan Ibrani). Mere- 
ka mempersembahkan korban bakaran sebagai mana mestinya di atas Mezbah. Mulai saat itu masyarakat Yahudi menambahkan satu hari libur untuk merayakan dua keajaiban. Keajaiban yang pertama, kemenangan atas orang Yunani, dengan keterbatasan jumlah orang dan peralatan, namun Allah memberikan kemenangan buat mereka. Kedua, kemenangan secara rohani, yang disimbolkan dengan menorah yang menyala selama delapan hari. Pada kenyataanya setelah peristiwa tersebut pasukan Yunani tetap ditempatkan di Yerusalem dan berusaha menaklukkannya kembali. Banyak pertempuran yang terjadi selama bertahun-tahun, hingga akhirnya konflik berakhir. Tahun 113 SM, pada pemerintahan raja Seleukus Demitrius II, dilakukanlah penandatanganan perjanjian damai dengan Simon, anak Mattathias yang masih hidup. Pada tahun itu, orang-orang Yahudi benar-benar terbebas dari kuk kafir.Simon, anak Mattathias adalah seorang imam besar yang agung, dan juga seorang jenderal dan pemimpin orang Yahudi. Melaluinya kedaulatan Yahudi atas tanah Israel secara resmi dipulihkan.

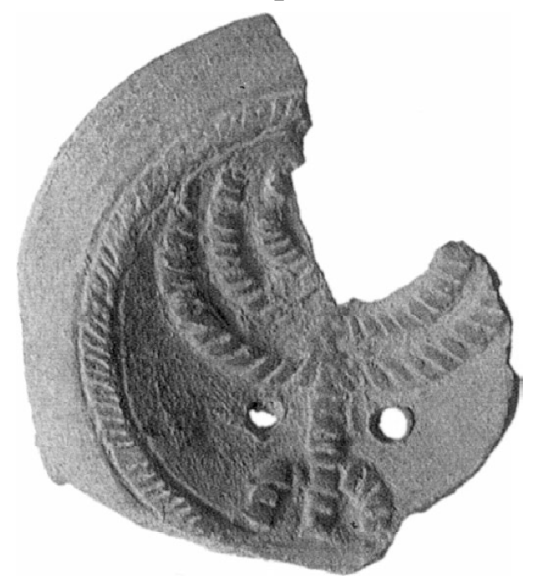

\section{Discus Lamp Fragment With Menorah} (Chancey,2003, p.184)

Sesuai aturan seharusnya Simon sebagai keturunan dari suku Lewi menjadi imam. Namun karena berbagai dorongan dan keinginannya sendiri, Simon memosisikan dirinya juga sebagai pangeran, meskipun dia tidak menyebut dirinya sebagai raja. Karena sebenarnya dia tahu betul bahwa seorang raja Yahudi hanya bisa datang dari jalur keturunan Daud. Tapi untuk semua tujuan praktis dia mengambil peran sebagai raja.Ini adalah pilihan yang bu- ruk bagi Simon karena keturunannya tidak menghormati perbedaan tersebut. Mereka memulai sebuah dinasti baru yang berkuasa di Israel dengan sebutan "Dinasti Hasmonean" yang berlangsung selama 101 tahun (138 SM- 37 SM) (Spiro, 2008, p.8). Dinasti ini ditandai dengan perluasan teritorial yang besar, tapi juga oleh kemerosotan moral dan agama yang tajam. Mereka seharusnya tidak menjadi raja sejak awal, lalu kemudian mereka menjadi raja yang rusak oleh sikap dan tingkah lakunya sendiri. Penguasa berikutnya adalah putra Simon, Johanan Hyrcanus, seorang yang kuat danpenguasa ambisius. Sebagian dari upayanya untuk memper-luas perbatasan Israel, dia secara paksa mengubah orang-orang yang baru ditaklukkan agar menjadi seperti Yahudi. Ini adalah sesuatu yang tidak pernah dilakukan dalam Yudaisme sebelum atau sesudahnya. Salah satu bangsa yang secara paksa dikonversi adalah Idumeans, mereka ini adalah keturunan Edom yang pindah ke Yehuda. Dan akibat cara yang demikian ini sangat merugikan orang Yahudi.

Di Israel, tidak jauh dari Beit Shemesh, ada situs arkeologi yang menarik dan terbuka untuk turis bernama Beit Guvrin Maresha. Terdiri dari ribuan Gua buatan manusia yang sebagian besar dipotong menjadi batu kapur empuk (Spiro, 2008, p.6). Ini satu dari kota-kota besar Idumeans.

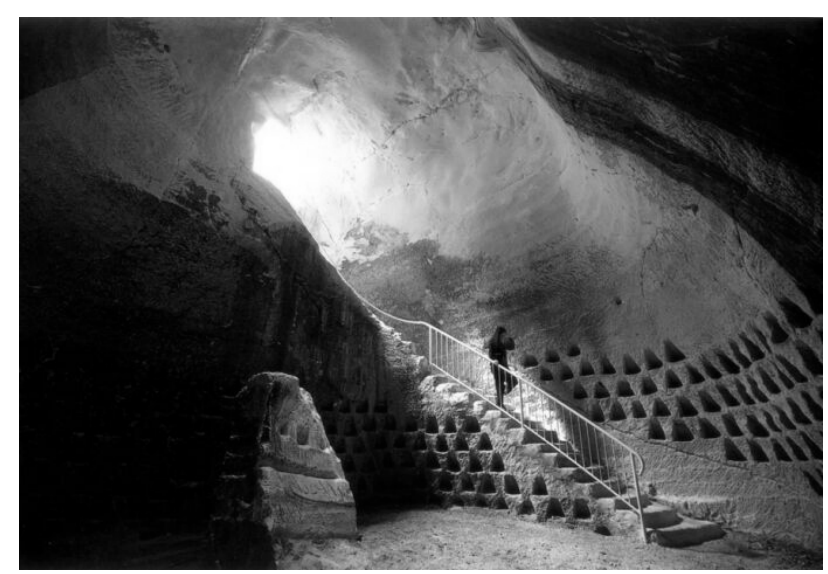

Beit Guvrin photo courtesy of Shlomo Aronson Architects (https://www.israel21c.org/the-land-of-a1000-caves)

Salah satu keluarga Idumean yang secara paksa dikonversi akan menjadi sangat signifikan un- 
tuk perannya dalam beberapa tahun kemudian selama invasi Romawi. Seorang keturunan keluarga ini bernama Herodes akan ditunjuk sebagai raja orang Yahudi dan dia menjadi penguasa yang kejam. Dia akan membunuh Imam Besar, anggota Mahkamah Agung Yahudi serta beberapa anggota keluarganya sendiri, tapi dia juga akan memulai serangkaian proyek bangunan fantastis yang akan mencakup kota Kaisarea, benteng di Masada, dan pembangunan kembali total Bait Suci.

Setelah kematian Johanan Hyrcanus, putranya, Judah Aristobulus menyatakan dirinya raja, tidak puas dengan gelar "pangeran" yang selama ini menjadi sebutan orang-orangnya terdahulu. Kaum Sanhedrin yang umum, yang telah bersedia memanggil Johanan dengan sebutan sebagai pangeran merasa keberatan dan menjadi marah.Rabbi Berel Wein di Echoes of Glory menulis hal ini: "Dia menganiaya para rabi dan pengikut Farisi mereka. Dia tanpa ampun mengasingkan banyak dari mereka, dan ratusan orang Farisi disakiti dan dieksekusi dengan kejam" (Chancey, 2003, p. 163).

Penguasa berikutnya Alexander Yanai (saudara Johanan Hyrcanus), dia sama seperti saudaranya, dia tidak bisa mentolerir orang-orang Farisi, dan dia telah melakukan eksekusi sekurang-kurangnya bagi delapan ratus orang. Selama eksekusi, Alexander Yannai menjadi tuan rumah sebuah pesta bergaya Yunani.Setelah kematian Yannai, jandanya, Ratu Salome, memerintah selama sembilan tahun. Dia adalah satu-satunya sinar terang dalam masa suram ini. Saudaranya adalah Simon benShatach, rabi terkemuka dari generasinya dan selama masa pemerintahannya ada kedamaian antara pimpinan dan rabi. Ini menjadi periode terakhirkedamaian dan stabilitas sejati untuk waktu yang sangat lama. Sejarah Dinasti Hasmonean adalah kasus klasik dari salah satu keluarga yang hebat yang dimulai dengan sangat terkenal, namun berakhir dengan sangat malang dan membuat orang Yahudi hancur.

Dua penguasa Hasmonean terakhir adalah anak-anak Salome - Hyrcanus dan Aristobolus - keduanya benar-benar Hellenized. Hyrcanus lebih le- mah dari Aristobolus, tapi dia mendapat dukungan yang kuat dari Antipater, seorang keturunan Idumean yang pindah ke Yudaisme, yang memiliki seorang anak laki-laki bernama Herodes. Kedua saudara ini berkelahi satu sama lain, karena mereka haus kekuasaan. Untuk menyelesaikan permasalahan mereka, maka mereka meminta bantuan Roma untuk menengahi perselisihan tersebut.

Mengundang orang-orang Romawi tidak seperti mengundang penjaga perdamaian multi-nasional. Tahun 63 SM, Jenderal Pompeii masuk Yerusalem dan membantai orang-orang Yahudi, dan menjadikan Hyrcanus penguasanya (Chancey, 2003, p. 164). Tahun 37 SM Antigonus (anak Aristobulos) dibunuh oleh orang Romawisehingga mengakhiri dinasti Hasmonean (Spiro, 2008, p. 8).

Menurut Cohen (2006, p. 10), peristiwa yang terjadi pada masa pemberontakan Maccabbee menunjukkan bahwa Allah akan memberikan reward kepada yang mengikuti jalan-jalan-Nya dan menghukum orang-orang yang tidak taat kepadaNya. Oleh sebab itu menurut pendapat penulis sejarah Maccabee ini menunjukkan bahwa Allah tetap bekerja sesuai peraturan yang telah ditetapkannya, baik secara perorangan maupun terhadap suatu bangsa. Ketika orang-orang Maccabbee hormat kepada Allah, seperti yang ditunjukkannya oleh mereka ketika tidak tunduk pada perintah manusia dan lebih menghormati Bait Allah, maka Allah membela mereka. Namun ketika mereka melanggar dengan menjadi raja, padahal mereka adalah keturunan Lewi yang sebenarnya diperkenankan untuk menjadi imam bagi Allah, mereka menjadi hancur.

\section{Peran Kerajaan Romawi pada Masa Intertestamen}

Roma sebagai negara dimulai tahun 500 SM dengan bentuk pemerintahan republik. Roma hanyalah negara kecil yang baru terbebas dari penguasaan Etrusca. Untuk memperkuat pertahanan negaranya, maka Roma meningkatkan kekuatan pemerintah dan angkatan perangnya. Dan karena kekuatan angkatan perangnya ini, akhirnya Roma bisa menguasai da- 
erah-daerah di Italia, Sicilia barat dan timur, dan Spanyol.

Daerah-daerah di kerajaan Makedonia yang merupakan daerah hellenistik pun akhirnya dikuasai oleh Roma. Roma terus mencapai kejayaannya pada zaman pemerintahan Caesar. Olehnya hampir sebagian dunia dikuasai. Setelah kematian Caesar, maka Octavianus, cucu kemenakannya menjadi ahli warisnya. Pada tahun 27 SM, Oktavianus terus memperkuat kekuasaan pemerintahnya dan secara tidak langsung, meskipun masih menghargai para senat, namun pada hakekatnya kekuasaan dominannya sebagai "Yang Mulia" atau "Augustus" lebih popular. Masa pemerintahan Augustus menandai dimulainya "pax Romana" atau "perdamaian Roma", tidak ada perang yang berarti, dari tahun 27 SM - 180 M (Sugihardjo, 1989, p. 109).

Posisi orang Yahudi sangat istimewa di masa Romawi, terutama karena hak istimewa yang diberikan kepada mereka oleh Julius Caesar (pemimpin Romawi). Caesar sangat menghormati Hyrcanus (seorang Yahudi) anak Alexander yang telah membantu Roma masuk ke Mesir. Hyrcanus seorang yang telah berani berperang untuk Roma, dengan membawa 1500 tentaranya menggempur Mesir. Caesar memutuskan untuk menjadikan Hycarnus dan keturunannya menjadi imam besar orang Yahudi dalam semua waktu sesuai dengan adat istiadat mereka dan mereka memberikan hak istimewa kepada imam besar beserta keturunannya.Selain itu, Caesar juga menulis kepada para hakim di wilayah Asia Minor, agar mencabut undang-undang yang melarang orang Yahudi untuk mematuhi adat istiadat bapak leluhurnya. Hak istimewa yang tercatat bagi orang-orang Yahudi di Roma meliputi hak berkumpul, mengumpulkan sumbangan dan makan bersama. Padahal bagi masyarakat religius umum Caesar melarangnya untuk berkumpul di kota.

Selain hal di atas, hal istimewa yang diberikan kepada orang Yahudi di Asia Kecil (Efesus) adalah tidak diwajibkannya mereka untuk mengikuti wajib militer. Hal ini didasarkan atas surat yang diberikan oleh gubernur Romawi, Publius Dolabella kepada para hakim dan dewan di Efesus tahun 43 SM. Gubernur menghormati ketaatan mereka kepada hari sabat dan pada hukum serta adat istiadat mereka; oleh karenanya mereka tidak diwajibkan dalam wajib militer.

Di Tirus pun orang-orang Yahudi mendapat perlakuan yang istimewa. Mark Antony mengirim surat ke hakim di Tirus dengan pernyataan bahwa semua yang telah dirampas dari orang Yahudi harus dikembalikan semuanya. Begitu pula bagi orangorang Yahudi yang sudah dijual sebagai budak, agar segera dibebaskan.Bila ada yang membangkang agar mereka tersebut dihukum berat.

Gubernur Gayus Norbanus Flaccus yang ada di Efesus menerima surat dari Augustus. Secara singkatnya menyatakan bahwa, "Pada tahun 27 SM, semua orang Yahudi di sekitar Mediterania berada di bawah kedaulatan kaisar Romawi. Augustus sangat menghormati orang-orang Yahudi, sehingga dia memerintahkan agar pengorbanan harus dilakukan setiap hari di Yerusalem sebagai penghormatan kepada Tuhan orang Yahudi. Korban ini adalah atas biayanya sendiri. Mereka diizinkan berkumpul dalam rumah ibadat, orang-orang Yahudi juga diperbolehkan untuk datang ke Yerusalem dari berbagai tempat untuk melakukan persembahan sulung kepada Tuhan di bait Suci.

Para penerus Augustus Octavianus (27 SM14 SM) adalah Augustus Tiberius (14 SM -37 M) dilihat dari waktu, maka Augustus inilah yang kemungkinan besar yang ikut mengadili Yesus sebelum penyaliban-Nya. Pada akhir hidupnya melarikan diri ke pulau Capri untuk mengungsi dari Roma dan dari musuh-musuhnya.Kemudian diteruskan oleh Augustus Caligula (37-41 M), akhir hidupnya menjadi gila dan bunuh diri. Penerusnya adalah Claudius (41-54 M), ia adalah paman dari Caligula, akhir hidupnya mati diracun oleh istrinya sendiri.Istrinya berniat menjadikan anaknya dari perkawinan pertamanya yang bernama Nero untuk dijadikan kaisar. Augustus Nero (54-68 M), membunuh ibu dan istrinya sendiri. Masa kaisar Nero ini banyak orang Kris- 
ten yang mengalami penganiayaan (Sugihardjo, 1989, p. 111).

Orang-orang Yahudi selama kepemimpinan Augustus Caligula mengalami penderitaan. Mereka benar-benar teraniaya oleh orang-orang Yunani. Namun setelah Caligula wafat tahun 41 SM, orangorang Yahudi bangkit kembali dan mulai mempersenjatai diri. Sehingga persiapan pertempuran sudah dimulai. Raja Agripa dan Herodes segera mengirim permohonan kepada Augutus Cladiusagar orangorang Yahudi di Alexandria, Syria, dan di seluruh wilayah di bawah kekuasaan Romawi untuk mendapatkan hak istimewa kembali.Dan suratnya ini mendapat sambutan yang baik dari Augustus Cladius. Melalui gubernur Romawi Mesir segera mengeluarkan sebuah dekrit yang menegaskan kembali hak istimewa orang-orang Yahudi yang telah dihilangkan oleh Caligula. Demikian juga diseluruh wilayah Romawi, Cladius menegaskannya kembali.

Kekaisaran Romawi memberikan hak istimewa kepada orang-orang Yahudi pada saat Augustus Octavianus dan Augustus Tiberius (27 SM-37 M) bertahta. Menurut Levine ini merupakan hak istimewa dari Allah yang diberikan kepada orang-orang Yahudi yang tersebar ke berbagai pelosok, agar semuanya bisa dijangkau dengan mudah dan dengan bahasa yang dapat dimengerti (Levine, 1998, p. 2628). Menurut penulis pun hal ini merupakan campur tangan dari Allah.Bagaimana bisa Yohanes Pembaptis memberitakan hal kerajaan Allah kepada semua orang dari seluruh Yudea, sekitar Yordan dan Yerusalem (Mat. 3: 1-6), jika tidak diberi kebebasan oleh Romawi.Begitu pula dengan aktivitas Yesus Kristus ketika berada di Yerusalem dan sekitarnya. Dia bisa mengajar di sinagog, mengajar orang banyak hingga jumlah pendengarnya lebih dari 5.000 orang, sering berkumpul untuk makan bersama dengan para murid-Nya, tentu hal-hal ini tidak bisa dilakukan, jika Augustus Romawi tidak memberikan hak istimewa kepada orang Yahudi.

Wilayah kekuasaan Romawi yang begitu luas hingga ke Mesir dan wilayah-wilayah lainnya pun merupakan campur tangan Ilahi. Hal ini untuk membuka jalan bagi pemberitaan kabar baik yang lebih luas dan juga tergenapinya rencana Allah. Hosea menubuatkan bahwa dari Mesir Kupanggil anak$\mathrm{Ku}$ itu (Hos.11:1). Ini tergenapi ketika Yesus yang terancam akan dibunuh oleh orang-orangnya Herodes dibawa ke Mesir oleh Yusuf dan Maria. Dan ketika raja Herodes telah wafat, maka Yesus dibawa kembali ke Yudea. Hal ini tidak mungkin terjadi, jika Mesir bukan daerah kekuasaan Romawi. Hal ini pun merupakan rancangan dari Tuhan yang sempurna.

Murid-murid, baik ketika masih ada Yesus di bumi maupun setelah naik ke Sorga, mereka dengan leluasa melakukan pemberitaan Injil ke berbagai daerah.Tentu hal ini merupakan campur tangan Tuhan. Melalui kekaisaran Romawi yang berkuasa, pemberitaan Injil lebih cepat meluas, karena berbagai wilayah berbahasa yang sama dan juga mendapat perlakuan yang sama dari kaisar Romawi.

\section{KESIMPULAN}

Dari runtutan sejarah dan berdasarkan beberapa teolog yang mengaitkan mengenai sejarah ini dengan campur tangan Allah, maka penulis meyakini bahwa masa dari Maleakhi (432 M) hingga Tuhan berbicara kepada imam Zakharia bapaknya Yohanes pembaptis merupakan masa Allah berkarya secara fantastis. Allah sedang mempersiapkan sesuatu hal yang besar bagi seluruh umat manusia. Allah tidak berdiam diri, justru Allah sedang merajut masa depan manusia untuk kekekalan.

Peristiwa yang terjadi dari mulai kerajaan Media Persia hingga kerajaan Romawi merupakan rentetan penggenapan penglihatan yang diberikan Allah kepada Daniel. Tuhan sedang berkarya melalui sejarah, dan hal itu terjadi pada masa intertiestamen. Hellenisasi danpenguasaan hampir setengah wilayah dunia oleh Yunani merupakan campur tangan Allah. Alkitab Perjanjian Lama diterjemahkan ke dalam bahasa dunia yakni bahasaYunani. Melalui hal ini tentu akanmemudahkan penyebaran Injil dengan bahasa yang dapat dimengerti semua orang dan bangsa. Juga penggenapan-penggenapan mengenai 
apa yang akan terjadi terhadap Kristus dan nubuatan para nabi mengenai tempat-tempat yang akan dilalui oleh-Nya. Contohnya Mesir dan Palestina merupakan sama-sama daerah yang dikuasai oleh Yunani, sehingga ketika Yunani ditaklukkan oleh Romawi maka daerah keduanya tetap ada dalam satu kekuasaan yang sama, dengan demikian nubuat tentang Kristus yang dinubuatkan oleh nabi Hosea "dari Mesir Kupanggil anak-Ku itu" dapat terealisasi. Yusuf dan Maria dengan mudah bisa masuk dan keluar dari Mesir. Begitu pula apa yang dilihat oleh Daniel bahwa kerajaan tersebut membinasakan banyak orang kudus dan juga melawan Raja segala

\section{DAFTAR RUJUKAN}

A. Chancey, Mark. 2003. The Archaelogy of Roman Palestine. Illinois.

H. Feldman, Louis. 1996. Jewish Life and Thought among Greeks \& Romans. Edinburgh: T \& T Clark Ltd.

Henry, Matthew. 2007. Tafsiran-tafsiran Alkitab ringkas. Alkipedia.

Israel 21c, The Land of a thousand Caves (https://www.israel21c.org/the-land-of-a1000-caves) diakses 20 Desember 2018.

Kalimi, Issac. 2005. The Reshaping of Ancient Israelity History in Chronicles. Indiana: Eisenbrouns.

Spiro, RabbiKen. 2008. The Revolt of the Maccabees. Jerusalem: Jewish pathway.

\section{LAI, 1997.Alkitab terjemahan baru.Jakarta.}

Beckwith, Roger. 2002.Intertestamental Judaism, its Literature and Its Significance.

Bennema, Cornelis. 2001. "The Strands of Wisdom

Tradion in Intertestaments and Characteristics." Tyndale Bulletin 2 (I): 61-82.

Cohen, Shaye J.D. 2006. From The Maccabees to The Mishnah. London. raja, telah terealisasi ketika pembinasaan dan penyiksaan terhadap anak-anak umat Tuhan dan penyaliban Kristus Yesus, Raja di atas segala raja berlangsung di bukit Golgota.

Peristiwa pemberontakan Maccabee menggambarkan bahwa pada masa intertestamentpun Allah tetap berkarya.Pada segala masa, firman-Nya tetap berlaku. Bagi orang-orang yang melakukan firman-Nya mendapat berkat dan pertolongan-Nya, sedang orang yang tidak taat, akan mengalami kehancuran. Masa Intertestament merupakan masa Allah berkarya. Tidak ada satu peristiwa pun yang luput dari pengendalian kekuasaan Allah.

Ekstrand, Donald W. 2004.The Intertestamental Period and Its Significance upon Christianity. t.t.: t.p.

Magness, Jody. 2012. The Archaeology of the Holy Land. Cambridge: Cambridge University Press.

Levine, Lee I. 1998. Judaism \& Hellenism In Antiquity, Conflict or Confluence? USA: The University of Washington Press.

Stalling D.G dan K.A Kichen. 2001. "Lahir, Kelahiran Kembali" dalam Yayasan Ensiklopedi Alkitab Masa Kini, Jilid II M-Z. Disunting H.A. Opusunggu. Diterjemahkan M. H. Simanungkalit. Jakarta: Yayasan Komunikasi Bina Kasih.

Guyatt, Nicholas. 2007. Providence and the Invention of the United States, 1607-1876. Cambridge University Press.

Sugihardjo, Sumobroto B.1989. Sejarah Peradaban Barat Klasik. Yogyakarta: Liberty.

Talmud, tractate Shabbat, 21b.

Taylor, G. 2005. Between The Testements. t.t.: t.p. Weyde, KarlWilliam. 2000. Prophecy and Teaching. New York: Wolter de Gruyter. 